\title{
Cultivation and characterization of symbiotic bacteria from the gut of Reticulitermes chinensis
}

\author{
Hao Fang ${ }^{1}$, Wen Chen ${ }^{1}$, Baojun Wang ${ }^{2}$, Xiaojuan $\mathrm{Li}^{1}$, Shuang-Jiang Liu ${ }^{2}$ and Hong Yang ${ }^{{ }^{*}}$ \\ ${ }^{1}$ Hubei Key Laboratory of Genetic Regulation and Integrative Biology, School of Life Sciences, Central China Normal \\ University, Wuhan 430079, People's Republic of China \\ ${ }^{2}$ State Key Laboratory of Microbial Resources, Institute of Microbiology, Chinese Academy of Sciences, Beijing, \\ 100101, People’s Republic of China
}

\begin{abstract}
The complex symbiotic relationship between wood-feeding termites and microorganisms inhabiting their intestinal tracts is a fascinating phenomenon in nature. To understand the physiological functions of symbiotic microorganisms, bacteria were isolated from the gut homogenate of Reticulitermes chinensis with different media and culture conditions. Under aerobic conditions, 105 bacterial strains were isolated with 1/5 LB medium, 1/3 TSB medium and a modified basal mineral medium, MM-4. Most dominant isolates were bacteria in the genera Bacillus (27.6\%) and Lactococcus (21.9\%). Under anaerobic conditions, 60 bacterial strains were isolated with 1/5 LB medium, 1/3 TSB medium and a modified Peptone-Yeast medium. The predominant isolates were bacteria in the genus Enterobacter (41.7\%) and Citrobacter (33.3\%). Many of these bacterial isolates shared high sequence similarity ( $>98 \%)$ in 16S rRNA genes to bacterial clones obtained from the same termite and the other wood-feeding termites or cockroaches. Several bacterial species such as Deinococcus and Gryllotalpicola were isolated from termite gut for the first time. Characterization of these isolates showed that (i) most of Enterobacteriaceae and Lactococcus strains were able to hydrolyze uric acid; and (ii) many of the Bacillus and Streptomyces strains presented endo- $\beta-1,4$-glucanase activity. The preliminary results of this work gave us hints of possible functions of symbiotic bacteria in nitrogen recycling and cellulose degradation in the gut of wood-feeding termites.
\end{abstract}

Keywords: nutrient dependent isolation, intestinal symbionts, wood-feeding termite, physiological function

*Correspondence to: Hong Yang, Hubei Key Laboratory of Genetic Regulation and Integrative Biology, School of Life Sciences, Central China Normal University, Wuhan 430079, People’s Republic of China; Email: hyang@mail.ccnu.edu.cn

Received: October 1, 2015; Accepted: February 16, 2016; Published Online: April 6, 2016

Citation: Fang H, Chen W, Wang B, et al. 2016, Cultivation and characterization of symbiotic bacteria from the gut of Reticulitermes chinensis. Applied Environmental Biotechnology, vol.1(1): 3-12. http://dx.doi.org/10.26789/AEB.2016.01.004.

\section{Introduction}

$\mathrm{W}$ ood-feeding termites can efficiently decompose lignocellulosic materials and play important roles in the carbon cycle in various ecosystems. The ability of cellulose degradation relies on the symbiotic association between wood-feeding termites and their intestinal symbionts ${ }^{[1]}$. The gut microbiota of wood-feeding lower termites comprises eukaryotes (protists), as well as prokaryotes (bacteria and archaea). Although evidences have showed that eukaryotes play important roles of cellulose degradation in lower termites ${ }^{[2,3]}$, the physiological functions of most prokaryotic symbionts are still not clear. Microscopic observation and molecular investigation showed that microbiota was extremely diversified in the gut of wood-feeding lower termites ${ }^{[4]}$. Cultureindependent investigations revealed that the dominant bacteria in the gut of wood-feeding lower termites such as Reticulitermes speratus and Reticulitermes san-

Cultivation and characterization of symbiotic bacteria from the gut of Reticulitermes chinensis. (C) 2016 Hao Fang, et al. This is an Open Access article distributed under the terms of the Creative Commons Attribution-NonCommercial 4.0 International License (http://creativecommons.org/licenses/bync/4.0/), permitting all non-commercial use, distribution, and reproduction in any medium, provided the original work is properly cited. 
tonensis were strict anaerobes like Spirochaetes, Elusimicrobia, Firmicutes and Bacteroides ${ }^{[5-7]}$. However, most of these bacteria have not been successfully cultivated and their physiological properties remained unclear. Under anaerobic conditions, nitrogen-fixing Enterobacter agglomerans was isolated from Coptotermes formosanus ${ }^{[8]}$. In addition, Streptococcus, Bacteroides, Enterococcus, and Enterobacter have been isolated from $R$. flavipes $^{[9,10]}$. More elegant experiments with specifically designed media led to the pure cultures of methanogens and spirochetes from the gut of R. flavipes and Zootermopsis angusticollis ${ }^{[11-14]}$. An attempt to isolate cellulolytic bacteria from the gut of $\mathrm{Z}$. angusticollis showed that some Cellulomonas, $\mathrm{Ba}$ cillus and Paenibacillus species can degrade carboxymethylcellulose $^{[15]}$. Despite all these efforts, compared with the huge diversity of prokaryotic symbionts in the gut of lower termites revealed by culture-independent methods, the amount of cultivated prokaryotic symbionts was still very small. More strategies including the use of low-nutrient media and nutrient-dependent media were needed for the cultivation of hitherto uncultured microbes ${ }^{[16,17]}$.

In this study, we tried to use a nutrient dependent isolation approach to cultivate so far uncultured bacterial symbionts from the gut of a wood-feeding lower termite, Reticulitermes chinensis (Snyder) (Isoptera: Rhinotermitidae). The preliminary characterization of the newly isolated bacterial strains gives us hints of possible physiological functions of symbiotic bacteria in the gut of wood-feeding lower termites.

\section{Materials and Methods}

\subsection{Collection of Termites}

A colony of $R$. chinensis was collected in Shizi Mountain, Wuhan, China. Termite species was identified by the analysis of morphological characteristics and mitochondrial cytochrome oxidase subunit II genes ${ }^{[18]}$. The colony was maintained in the laboratory in polyethylene containers on a diet of pine wood and water. Only worker termites were used in the experiments.

\subsection{Culture Media and Isolation of Bacteria}

Bacteria were isolated from gut homogenates of 10 worker larvae under aerobic conditions with three media, a fivefold diluted LB medium (1/5 LB, g/L: Tryptone, 2; Yeast extract, 1; $\mathrm{NaCl}, 2)$, a threefold diluted tryptic soy broth (1/3 TSB, 10 g/L TSB, Bacto; Becton Dickinson), and a modified basal mineral me- dium, MM-4 ${ }^{[19]}$. To prepare the solid medium, $15 \mathrm{~g}$ agar was added to per liter of each medium. Under anaerobic conditions bacteria were isolated from gut homogenates of 10 worker larvae with the $1 / 5 \mathrm{LB}$ medium, the 1/3 TSB medium, and a modified Peptone-Yeast medium (PY, g/L: Refined tryptone 0.5; Tryptone $0.5 ; \mathrm{KH}_{2} \mathrm{PO}_{4} \quad 0.2 ; \mathrm{Na}_{2} \mathrm{HPO}_{4} \cdot 12 \mathrm{H}_{2} \mathrm{O} \quad 0.5$; $\mathrm{NH}_{4} \mathrm{Cl}$ 0.3; $\mathrm{MgSO}_{4} \cdot 7 \mathrm{H}_{2} \mathrm{O} 0.02 ; \mathrm{CaCl}_{2} \cdot 2 \mathrm{H}_{2} \mathrm{O} 0.1$; Fe$\mathrm{SO}_{4} \cdot 7 \mathrm{H}_{2} \mathrm{O}$ 0.02; Sterile water $1 \mathrm{~L} ; \mathrm{pH} 7.0$ ). For all the three anaerobic media, $0.5 \mathrm{~g} / \mathrm{L} \mathrm{L}$-cysteine was used as a reductant and resazurin $(10 \mathrm{mg} / \mathrm{L})$ was used as an oxygen indicator. A trace element solution ${ }^{[20]}$ and a seven-vitamin solution ${ }^{[21]}$ were filtered through a 0.22 $\mu \mathrm{m}$ membrane (Millipore, MA, USA) and added to each medium as supplements. Gut dissection and homogenate preparation were conducted according to the method reported previously ${ }^{[19]}$. For the isolation of aerobic bacteria the homogenates were serially diluted (1:10) and inoculated to three different agar plates (triplicate series) and incubated at $30^{\circ} \mathrm{C}$ for 10 to 14 days. For the isolation of anaerobic bacteria, all media and utensils were degassed and charged with $\mathrm{N}_{2}$ for several times to remove oxygen before use. Termites were dissected and the gut homogenates were prepared in a glove box under the atmosphere of $\mathrm{N}_{2}(2-5 \%$ $\mathrm{H}_{2}$ ). The diluted homogenates were first inoculated in liquid media at $30^{\circ} \mathrm{C}$ for 10 to 20 days to enrich cultures and then transferred into different agar plates (triplicate series) and incubated at $30^{\circ} \mathrm{C}$ in the glove box. Morphologically distinct bacterial colonies were collected from each agar plate and purified after three times of subculture.

\subsection{Characterization of Bacterial Isolates}

Bacterial isolates were identified based on 16S rRNA genes with universal primers $27 \mathrm{~F}^{[22]}$ and $1492 \mathrm{R}^{[23]}$. Polymerase chain reaction (30 cycles) was carried out as described previously ${ }^{[7]}$. PCR products were digested with restriction enzymes Msp I and Hae III for aerobic cultivation and with Msp I and Afa I for anaerobic cultivation to sort the isolates according to RFLP profiles. 16S rRNA genes of isolates with different RFLP patterns were sequenced and edited using Lasergene Seqman (DNASTAR, UK) and checked for chimeras using the Pintail chimera check program ${ }^{[24]}$.

The capability of uric acid nitrogen utilization of anaerobic and facultative anaerobic isolates was determined with the method modified from Potricus and Breznak (1980) ${ }^{[25]}$. Briefly, bacterial cells were inocu- 
lated in the anaerobic chamber on BHIU plates comprised double-layer agar (1.5\%) of brain-heart infusion (3.7\%, Difco), $1.0 \%$ and $0.1 \%$ of UA, respectively, in both the top and the bottom layers. The inoculated plates were incubated at $30^{\circ} \mathrm{C}$ for $5-15$ days. The colonies surrounded by a clear zone in the otherwise opaque medium were counted as uricolytic bacteria.

The capability of cellulose degradation of aerobic isolates was determined by screening the activity of endo- $\beta$-1, 4-glucanase (EG) on Congo red agar plates with the CMCNa (Carboxymethylcellulose sodium salt) as substrate ${ }^{[26]}$. Bacterial isolates with the activity of endo- $\beta-1$, 4-glucanase were detected based on the clear hydrolysis zones on the agar plates.

\subsection{Phylogenetic Analysis}

Sequences obtained were compared with the published sequences in GenBank using Blast from NCBI (http: //www.ncbi.nlm.nih.gov/BLAST). Fasta files of trimmed sequences were input into RDP online alignment tool $^{[27]}$ and aligned according to secondary structure of 16S rRNA genes. Phylogenetic trees were constructed with MEGA5 package ${ }^{[28]}$ based on the alignments of 1350-bp sequences using maximum likelihood method with Jukes-Cantor model. Bootstrap analysis with 1000 replicates was performed to determine the statistical significance of the branching order.

\section{Results}

\subsection{Bacterial Isolates Obtained from Aerobic and Anaerobic Cultivation}

Under aerobic conditions, a total of 105 bacterial strains were isolated from three media and were identi- fied as 24 different bacterial species based on the characteristics of morphology and 16S rRNA genes as showed in Table 1. Most of these isolates belonged to three bacterial phyla, Firmicutes (59.0\%), Proteobacteria (28.6\%) and Actinobacteria (7.6\%). Within Firmicutes, all bacterial isolates were affiliated with four genera, Bacillus, Lactococcus, Paenibacillus and Staphylococcus with the proportions of $27.6 \%, 21.9 \%, 7.6 \%$ and $1.9 \%$, respectively. Most of the Proteobacteria isolates were affiliated with the family Enterobacteriaceae in $\gamma$-Proteobacteria subgroup, among them Enterobacter (12 strains) and Dyella (11 strains) were the dominant ones. The other bacterial isolates were affiliated with the phyla Deinococcus-Thermus, Verrucomicrobia and Bacteroidetes. Interestingly, one of the bacterial strains (strain TM1) shared 16S rRNA gene sequence similarity less than $94 \%$ with those of all the other cultivated bacterial strains, which has been characterized to be a new species in the genus Deinococcus ${ }^{[19]}$. Five of the bacterial isolates (strains TSB94, TSB14, TSB56, TSB47 and LB17) shared similarity less than $98 \%$ in their 16S rRNA genes with all the other cultivated bacterial strains (Table 1). Under anaerobic conditions, 60 bacterial strains were isolated from the gut of $R$. chinensis with 1/3 TSB, 1/5 LB and a modified PY medium as showed in Table 2. The strains were identified as 7 distinct bacterial species based on the morphological properties and $16 \mathrm{~S}$ rRNA genes. All these bacterial isolates belonged to 6 genera in two bacterial phyla, Proteobacteria (88.3\%) and Firmicutes (11.7\%). Among these isolates, bacteria affiliated with Enterobacter and Citrobacter in the family Enterobacteriaceae were most abundant ones with the proportions of $41.7 \%$ and $33.3 \%$ in all isolated strains, respectively.

Table 1. Bacteria isolated from Reticulitermes chinensis under aerobic condition

\begin{tabular}{llrcr}
\hline Phylogenetic affiliation & Type strains* & No. of strains & $\begin{array}{c}\text { GenBank acc. No. of } \\
\text { 16S rRNA gene }\end{array}$ & Most closely related species (clones)/GenBank acc. No./Similarity \\
\hline Firmicutes & & & & \\
Lactococcus & TSB55 & 15 & JQ864363 & Unc. bacterial clone CR_51, JX457182, 99\% \\
& TSB94† & 8 & JQ864364 & Unc. Lactococcus clone Rs-B70, AB089061, 99\% \\
Bacillus & LB4 & 3 & JQ864365 & Bacillus sp. KZ_AaeF_Ma1, GU726175, 99\% \\
& LB18 & 3 & JQ864366 & Bacillus firmus, HM030743, 99\% \\
Paenibacillus & TSB100 & 23 & JQ864367 & Bacillus endophyticus KC851835, 99\% \\
& TSB49 & 2 & JQ864368 & Paenibacillus sp. TSW02, AB663503, 99\% \\
& TSB65 & 4 & JQ864369 & Paenibacillus sp. K-58, EU497638, 99\% \\
Staphylococcus & TSB106 & 2 & JQ864370 & Paenibacillus ginsengagri, AB245383, 99\% \\
& TSB33 & 1 & JX291543 & Staphylococcus sp., JF899874, 100\% \\
& TSB52 & 1 & JX291544 & Staphylococcus epidermidis, AB680360, 100\% \\
\hline
\end{tabular}




\section{Continued}

\begin{tabular}{|c|c|c|c|c|}
\hline Phylogenetic affiliation & Type strains* & No. of strains & $\begin{array}{l}\text { GenBank acc. No. of } \\
\text { 16S rRNA gene }\end{array}$ & Most closely related species (clones)/GenBank acc. No./Similarity \\
\hline \multicolumn{5}{|l|}{ Proteobacteria } \\
\hline Spingomonadaceae & TM7 & 1 & JQ864386 & Sphingomonadaceae bacterium, AB220140, 99\% \\
\hline \multirow[t]{2}{*}{ Burkholderia } & TM6 & 1 & JQ864384 & Burkholderia sp. SBH-16, AB366338, 99\% \\
\hline & TSB14 $\dagger$ & 3 & JQ864385 & Unc. Burkholderia clone Rc582, JQ617842, 99\% \\
\hline \multirow[t]{3}{*}{ Enterobacter } & LB9 & 4 & JQ864377 & Enterobacter amnigenus, HQ242724, 99\% \\
\hline & TSB75 & 3 & JQ864378 & Enterobacter sp. TM1-4, DQ068923, 99\% \\
\hline & TM2 & 5 & - & Enterobacter sp. TM1-4, DQ068923, 99\% \\
\hline Trabulsiella & LB10 & 2 & JQ864379 & Trabulsiella odontotermitis, DQ453130, 99\% \\
\hline \multirow{2}{*}{ Dyella } & LB15 & 1 & JQ864383 & Dyella sp. ST6D, GU458291, 99\% \\
\hline & TSB78 & 10 & - & Dyella sp. ST6D, GU458291, 99\% \\
\hline \multicolumn{5}{|l|}{ Actinobacteria } \\
\hline \multirow[t]{3}{*}{ Streptomyces } & TSB31 & 3 & JQ864371 & Streptomyces sp. TA4-8, AB562508, 100\% \\
\hline & TSB67 & 3 & JQ864372 & Streptomyces griseus, EF588223, 99\% \\
\hline & TM10 & 1 & JQ864373 & Streptomyces sp. 23bC, HM235460, 99\% \\
\hline Gryllotalpicola $\dagger$ & TSB56 & 1 & JQ864374 & Gryllotalpicola daejeonensis. HQ832502, 98\% \\
\hline \multicolumn{5}{|l|}{ Verrucomicrobia } \\
\hline Opitutaceae† & TSB47 & 2 & JQ864375 & Opitutaceae sp. TAV1, AY587231, 98\% \\
\hline \multicolumn{5}{|l|}{ Deinococcus-Thermus } \\
\hline Deinococcus $\dagger$ & TM1 & 1 & HM214546 & Deinococcus gobiensis, EU427464, 94\% \\
\hline \multicolumn{5}{|l|}{ Bacteroidetes } \\
\hline Chryseobacterium $\dagger^{\dagger}$ & LB17 & 2 & JQ864376 & Chryseobacterium sp. PHD-9, DQ301786, 98\% \\
\hline
\end{tabular}

*: Strains isolated from 1/5 LB were designated as LB; Strains isolated from 1/3 TSB were designated as TSB; Strains isolated from a modified basal Mineral Medium, MM-4 were designated as TM.

-: 16S rRNA gene sequences of the strains were the same as those of the other strains and were not submitted.

$\dagger$ : Strains with $16 \mathrm{~S}$ rRNA gene similarity lower than $98 \%$ compared with the other isolates in the environments.

Table 2. Bacteria isolated from Reticulitermes chinensis under anaerobic condition

\begin{tabular}{|c|c|c|c|c|}
\hline Phylogenetic affiliation & Type strains & No. of strains & $\begin{array}{l}\text { GenBank acc. No. of } \\
\text { 16S rRNA gene }\end{array}$ & $\begin{array}{l}\text { Most closely related species (clone)/ } \\
\text { GenBank acc. No./Similarity }\end{array}$ \\
\hline \multicolumn{5}{|l|}{ Firmicutes } \\
\hline \multirow[t]{2}{*}{ Lactococcus } & TSB6 & 2 & JX291541 & Lactococcus lactis, HQ591349, 99\% \\
\hline & TSB11 & 3 & JX291542 & Unc. Lactococcus clone Rc598, AB522148, 99\% \\
\hline Staphylococcus & LB7 & 2 & JX291545 & Staphylococcus sp., FJ380997, 100\% \\
\hline \multicolumn{5}{|l|}{ Proteobacteria } \\
\hline \multirow{3}{*}{ Enterobacter } & TSB7 & 7 & JX291546 & Enterobacter sp. RsN-1, AB673456, 99\% \\
\hline & LB2 & 4 & - & Enterobacter sp. TM1-4, DQ068923, 99\% \\
\hline & PY8 & 14 & - & Enterobacter sp. TM1-4, DQ068923, 99\% \\
\hline \multirow{3}{*}{ Citrobacter } & TSB4 & 6 & JQ864380 & Citrobacter sp. PM2, GU458277, 99\% \\
\hline & LB4 & 1 & - & Citrobacter sp. PM2, GU458277, 99\% \\
\hline & PY2 & 13 & - & Citrobacter sp. PM2, GU458277, 99\% \\
\hline \multirow{2}{*}{ Yokenella } & TSB2 & 3 & JQ864382 & Yokenella strain CIP, JN175339, 99\% \\
\hline & LB1 & 1 & - & Yokenella strain CIP, JN175339, 99\% \\
\hline Stenotrophomonas & TSB10 & 4 & JQ864381 & Stenotrophomonas maltophilia, JQ579644, 99\% \\
\hline
\end{tabular}

*: Strains isolated from 1/5 LB were designated as LB; Strains isolated from 1/3 TSB were designated as TSB; Strains isolated from modified Peptone-Yeast medium were designated as PY.

-: 16S rRNA gene sequences of the strains were the same as the other strains and were not submitted. 


\subsection{Phylogenetic Affiliation of Bacterial Isolates}

Phylogenetic analysis showed that all the isolated bacterial strains in the phylum Firmicutes were affiliated with four genera (Lactococcus, Bacillus, Paenibacillus and Staphylococcus) (Figure 1). Further analysis showed that many of the isolated strains shared high similarity in 16S rRNA genes to those of the uncultured bacterial clones obtained from the same termite or the other termites and wood-feeding cockroaches. For example, Lactococcus strain TSB11 (JX291542) shared 99\% sequence similarity in 16S rRNA genes with those of the Lactococcus clone Rc598 (JQ617828) retrieved from the same termite, $R$. chinensis. Strain TSB94 (JQ864364) shared sequence identity higher than 99\% in 16S rRNA genes with those of the Lactococcus clone Rs-B70 retrieved from R. speratus $^{[6]}$, whereas Strain TSB55 (JQ864363) shared 99\% sequence similarity with an uncultured bacterial clone CR_ 51 retrieved from a wood-feeding cockroach (Figure 1).

Phylogenetic analysis showed that many bacterial isolates were affiliated with several subgroups of Proteobacteria especially Gammaproteobacteria (Figure 2). An Enterobacter strain TSB7 (JX291546) shared sequence similarity higher than $98 \%$ in 16S rRNA genes with those of the bacterial isolate $\mathrm{RsN}-1^{[29]}$ and clone Rs-M74 ${ }^{[6]}$ retrieved from $R$. speratus. The Citrobacter strain TSB4 was closely related to a Citrobacter strain isolated from $R$. speratus ${ }^{[30]}$ whereas the

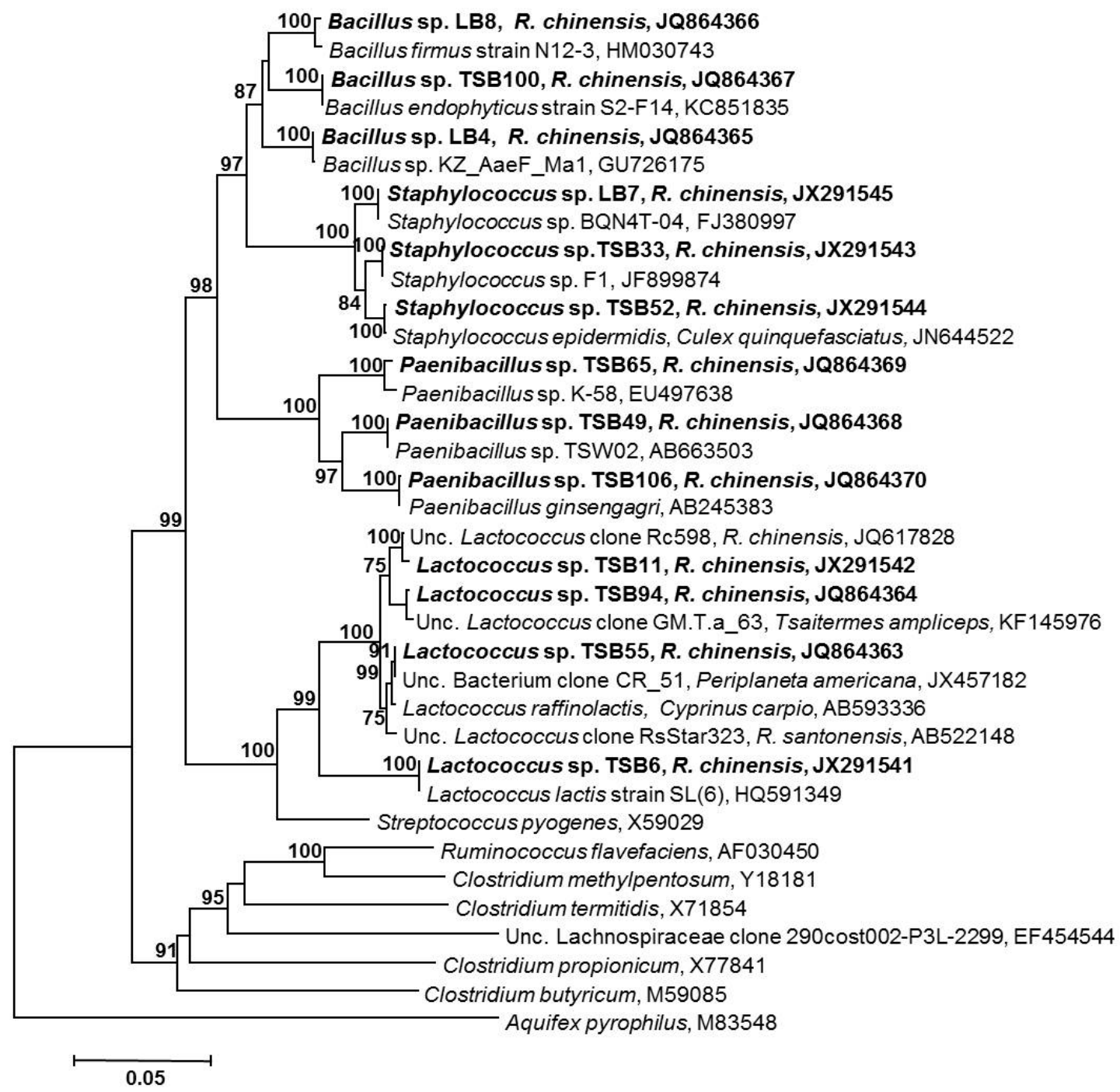

Figure 1. Phylogenetic tree of isolated Firmicutes strains.

Phylogenetic tree of Firmicutes isolates constructed with the maximum likelihood method of Mega 5 based on the 16S rRNA gene sequences. Bacterial isolates obtained from this study were showed in bold. Aquifex pyrophilus was used as an outgroup. Bootstrap values (1000 replicates) higher than $75 \%$ were shown. Bar represents $5 \%$ sequence divergence. 


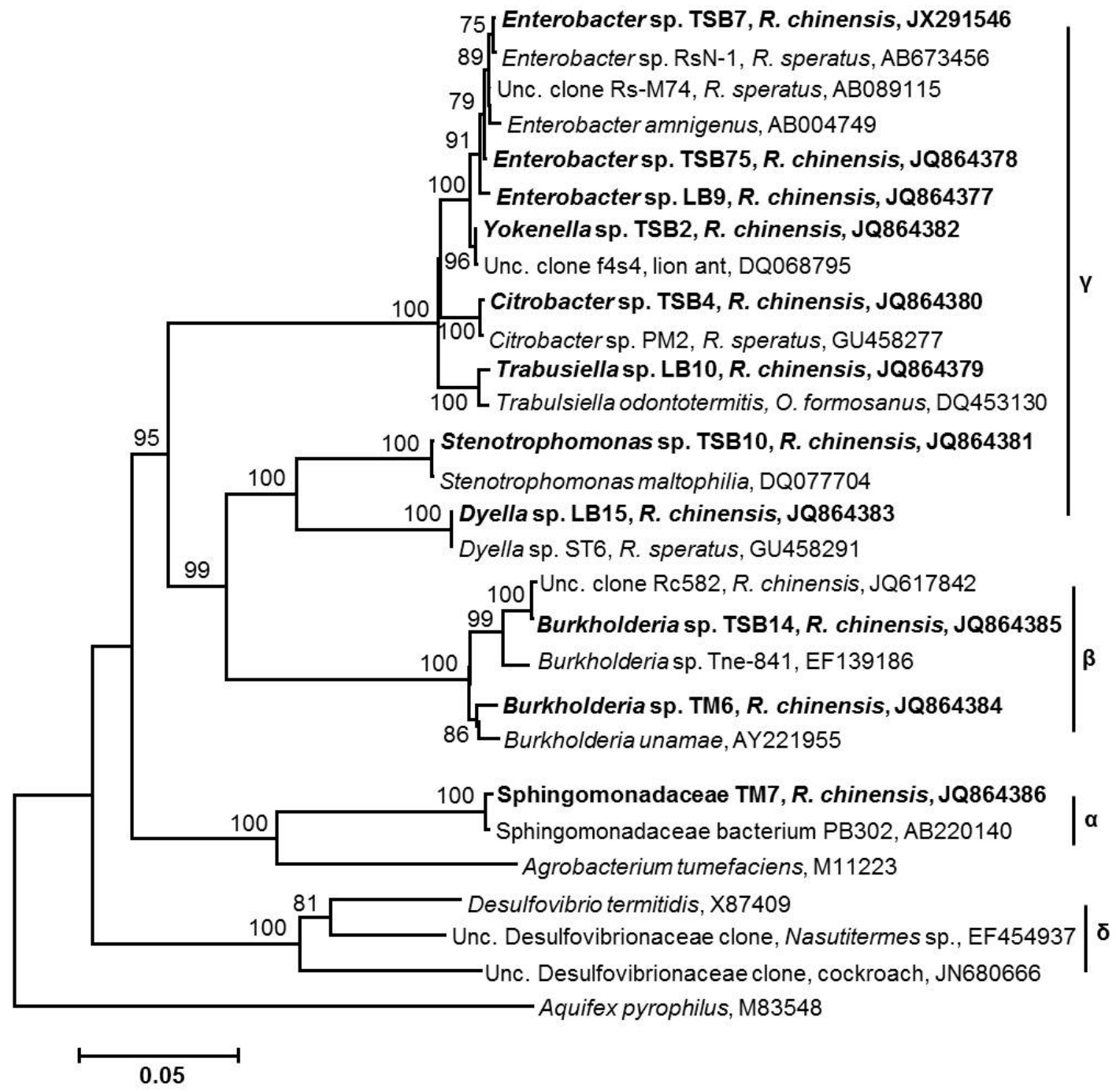

Figure 2. Phylogenetic tree of isolated Proteobacteria strains.

Phylogenetic tree of Proteobacteria isolates constructed with the maximum likelihood method of Mega 5 based on the 16S rRNA gene sequences. Bacterial isolates obtained from this study were showed in bold. Aquifex pyrophilus was used as an outgroup. Bootstrap values (1000 replicates) higher than $75 \%$ were shown. Bar represents $5 \%$ sequence divergence.

Trabulsiella strain LB10 was closely related to $T$. odontotermitis isolated from the fungus-cultivating termite, Odontotermes formosanus ${ }^{[31]}$. These bacterial isolates were grouped with their close relatives and formed the $\gamma$-Proteobacteria cluster in the phylogenetic tree (Figure 2). In addition, the 16S rRNA genes of strain TSB14 (JQ864385) were similar to those of Burkholderia clone Rc582 (JQ617842) retrieved from the same termite ( $R$. chinensis) with sequence divergence less than $1 \%$. All these Burkholderia strains including strain TM6 formed the $\beta$-Proteobacteria cluster.

\subsection{Characterization of Major Groups of Cultiva- ble Bacteria}

Clear zone-forming experiment for anaerobic and fa- cultative anaerobic bacterial isolates revealed that many of these strains especially those belonging to the family Enterobacteriaceae and Streptococcaceae can hydrolyze uric acid as showed in Table 3. The uricolytic active bacterial strains showed clear hydrolysis zones on the BHIU plates after the inoculation and incubation for 5-15 days. The capability of the use of uric acid indicated that these bacteria might involve in nitrogen recycling in the intestine of $R$. chinensis.

The screen of cellulose degradation capability of aerobic strains with CMCNa Congo Red plates showed that most of the Bacillus isolates (TSB100) and part of the Streptomyces strains (TSB67) have endo- $\beta$-1,4-glucanase activities, indicating that these bacteria might involve in cellulose degradation in the gut 
Hao Fang, Wen Chen, Baojun Wang, et al.

Table 3. Uricolytic activity of anaerobic and facultative anaerobic bacteria isolated from the gut of Reticulitermite chinensis

\begin{tabular}{|c|c|c|c|c|}
\hline Phylogenetic affiliation & Type strain & $\begin{array}{c}\text { Closest relative species (clone) / GenBank acc. } \\
\text { No. / Similarity }\end{array}$ & No. of strains & Uricolytic activity \\
\hline \multirow[t]{4}{*}{ Enterobacter } & LB9 & Enterobacter amnigenus, HQ242724, 99\% & 4 & - \\
\hline & TSB75 & Enterobacter sp. TM1-4, DQ068923, 99\% & 24 & + \\
\hline & TSB7 & Enterobacter sp. RsN-1, AB673456, 99\% & 7 & - \\
\hline & PY8 & Enterobacter sp. TM1-4, DQ068923, 99\% & 18 & + \\
\hline Trabulsiella & LB10 & Trabulsiella odontotermitis, DQ453130, 99\% & 2 & + \\
\hline Citrobacter & TSB4 & Citrobacter sp. PM2, GU458277, 99\% & 20 & + \\
\hline Yokenella & TSB2 & Yokenella strain CIP, JN175339, 99\% & 4 & + \\
\hline Stenotrophomonas & TSB10 & Stenotrophomonas maltophilia, JQ579644, 99\% & 4 & - \\
\hline \multirow[t]{4}{*}{ Lactococcus } & TSB55 & Unc. bacterial clone CR_51, JX457182, 99\% & 15 & + \\
\hline & TSB94 & Unc. Lactococcus clone Rs-B70, AB089061, 99\% & 8 & - \\
\hline & TSB6 & Lactococcus lactis, HQ591349, 99\% & 2 & + \\
\hline & TSB11 & Unc. Lactococcus clone Rc598, AB522148, 99\% & 3 & + \\
\hline \multirow[t]{2}{*}{ Staphylococcus } & TSB33 & Staphylococcus sp., JF899874, 100\% & 1 & - \\
\hline & TSB52 & Staphylococcus epidermidis, AB680360, 100\% & 1 & + \\
\hline Chryseobacterium & LB17 & Chryseobacterium sp.PHD-9(DQ301786) 98\% & 2 & - \\
\hline Opitutaceae & TSB47 & Opitutaceae sp. TAV1, AY587231, 98\% & 2 & - \\
\hline
\end{tabular}

of $R$. chinensis. The other aerobic isolates like Paenibacillus, Burkholderia and Chryseobacterium did not present endoglucanase activities.

\section{Discussion}

\subsection{Cultivation Strategies and the Diversity of Cul- tivable Bacteria}

It was reported that less than $1 \%$ microorganisms are cultivable in natural environments ${ }^{[32]}$. Although microbiologists have made great efforts to cultivate bacteria from the gut of various termites since decades, so far most of the key bacterial symbionts have not been successfully isolated ${ }^{[1]}$.

Obviously more diverse bacterial species were isolated in this study compared with previous researches. Bacteria affiliated with fourteen genera in six families were isolated under aerobic conditions (Table 1), whereas bacteria in only seven genera of three families were obtained from R. speratus ${ }^{[30]}$. Except strict aerobes like Bacillus and Paenibacillus, many facultative anaerobes like Lactococcus, Enterobacter, Chryseobacterium, etc. were isolated under aerobic conditions from R. chinensis. Meanwhile, Lactococcus and bacteria affiliated with several genera in the family Enterobacteriaceae were successfully isolated under anaerobic conditions, as the results of previous researches on the other wood-feeding termites ${ }^{[9,10]}$. In addition to these, bacteria in several genera, e.g. Deinococcus and Gryllotalpicola were first reported to be isolated from termite guts and were characterized as new bacterial species ${ }^{[19,33]}$. Previously Streptomytes were isolated only from higher termites like Macrotermes, Amitermes and Microcerotermes ${ }^{[34,35]}$. In this study, seven Streptomytes strains (strains TSB31, TSB67 and TM10) were first isolated from $R$. chinensis, a lower termite. The higher diversity of cultivable bacteria indicated that the strategies used in current study are efficient for the cultivation of hitherto uncultivated bacteria from termite gut. Compared with anaerobic cultivation, more bacterial species were isolated under aerobic conditions. Although bacteria in several genera like Lactococcus, Staphylococcus and Enterobacter were isolated from both aerobic and anaerobic conditions, the phylotypes of those isolates in the same genus were different.

Under aerobic conditions, bacteria affiliated with ten genera were isolated from 1/3 TSB medium, whereas bacteria affiliated with five genera were obtained from 1/5 LB medium and MM-4 medium, respectively (Table 1). Most of the bacteria isolated from 1/5 LB medium (e.g. Trabulsiella, Chryseobacterium) and MM-4 medium (e.g. Spingomonadaceae, Burkholderia and Deinococcus) were phylogenetically different from those obtained from 1/3 TSB medium, indicating that the type of cultivable bacteria were nutrient-dependent. Compared with 1/3 TSB medium and 1/5 LB medium, MM-4 medium was less nutrient abundant, 
from which a new bacterial strain (strain TM1) that shared 16S rRNA gene sequence similarity less than $94 \%$ to all the other bacterial isolates was isolated, indicating that the use of oligotrophic medium was efficient to get new bacterial species. The results obtained from this study confirmed that the use of lownutrient and oligotrophic media was an efficient strategy to get higher diversity of cultivable bacteria and possibly more new bacterial species ${ }^{[16,36]}$.

\subsection{Phylogeny of the Cultivable Bacteria}

Although many bacteria were isolated from various termite guts ${ }^{[37]}$, very few studies showed the phylogenetic relationships between cultivated bacteria and bacterial clones obtained from the 16S rRNA gene clone libraries established from various termites. In general, previous work showed that the dominant bacterial groups revealed by culture-dependent and culture-independent approaches were quite different. Interestingly, many bacterial isolates obtained from current study shared high similarity (> 98\%) in their 16S rRNA genes to the bacterial clones retrieved also from the same termite host or the other wood-feeding lower termites and cockroaches. The bacterial pure cultures form the basis for further studies of physiological functions of bacteria in the complex microbes-termites symbiotic system.

\subsection{Physiological Functions of Cultivable Bacteria}

Wood-feeding termites live on cellulolytic materials that are typically lack of nitrogen sources in their diet, therefore nitrogen fixation and recycling is very important for their nutrition ${ }^{[38,39]}$. Unlike Enterobacter isolates obtained from C. formosanus ${ }^{[8]}$ and Mastotermes darwiniensis ${ }^{[40]}$, our study showed that all Enterobacter isolates and other Enterobacteriaceae isolates did not have nitrogen fixation activities (data not shown). Interestingly, most of the Enterobacteriaceae isolates, e.g. Enterobacter, Trabulsiella and Citrobacter strains, can utilize uric acid nitrogen (Table 3). An earlier study on $R$. speratus and Coptotermes formosanus also showed that Enterobacter strains isolated from lower termites can hydrolyze uric acid nitrogen ${ }^{[30]}$. However, no uricolytic Trabulsiella and Citrobacter strains were isolated from those termites. Compared with the previous study, relatively higher diverse uricolytic bacteria were isolated from $R$. chinensis.

Lactococcus strains were often isolated from termite gut homogenates. The 16S rRNA genes of Lactococcus were also frequently detected from termite clone libraries $^{[37,38]}$, indicating that these bacteria play important roles in the gut of termites. Previous studies showed that Lactococcus may ferment sugars to lactate when oxygen was limited in termite guts ${ }^{[9,10,41]}$. This study showed that in addition to sugar fermentation, most of the Lactococcus strains can utilize uric acid in vitro (Table 3), as Lactococcus strain CD31 isolated from Cryptotermes domesticus ${ }^{[30]}$. The results indicated that Lactococcus might also involve in nitrogen metabolism by the recycling of uric acid nitrogen in termite guts.

Unlike the use of selected media with specific substrates, different bacterial isolates in the same lineage obtained from this study presented functional divergence. All Bacillus strains isolated from Z. angusticollis with the media containing wood or filter paper showed endo- $\beta$-1, 4-glucanase activity, either strong or weak ${ }^{[15]}$. Most of the Bacillus isolates in this study (represented by strain TSB100) showed high endo- $\beta-1$, 4-glucanase activity. However, some other Bacillus isolates such as LB18 did not present endo- $\beta$-1, 4-glucanase activity. The same is true for Streptomytes isolates, among which only strain TSB67 presented endoglucanase activities. Streptomytes strains isolated from higher termites had been proved to have lignin peroxidase activity and can degrade lignin ${ }^{[34,35]}$. Whether the Streptomytes strains obtained from $R$. chinensis can degrade lignin or not, requires further analysis.

\section{Conclusion}

In conclusion, the application of nutrient dependent isolation approaches is an efficient strategy to isolate bacteria from the gut of $R$. chinensis under both aerobic and anaerobic conditions. A higher diversity of bacteria and more new bacterial species were isolated compared with previous studies. Many bacterial isolates were phylogenetically closely related to bacterial clones obtained from the same termite or other termites, which is significant for the further research of the symbiotic relationship between bacteria and termites. Biochemical and physiological studies showed that in addition to uric acid nitrogen recycling, symbiotic bacteria may also involve in lignocellulose degradation in the gut of wood-feeding termites, such as $R$. chinensis.

\section{Author Contributions}

Fang $\mathrm{H}$ is responsible for the characterization of isolated bacteria; Chen W and Wang B isolated bacteria under aerobic conditions; Li X isolated bacteria under 
anaerobic conditions; Liu S-J and Yang $\mathrm{H}$ designed the experiments and analyzed the results.

\section{Conflict of Interest and Funding}

No conflict of interest was reported by the authors.

\section{Acknowledgements}

This study was supported by National Natural Science Foundation of China (30970001, 31170004), State Key Laboratory of Microbial Resources, Institute of Microbiology, CAS (Open Project: SKLMR-20110605) and the project of Hubei Key Laboratory of Genetic Regulation and Integrative Biology (Grant No. GRIB201509).

\section{References}

1. Brune A, 2014, Symbiotic digestion of lignocellulose in termite guts. Nature Reveiws Microbiology, vol.12(3): 168-180. http://dx.doi.org/10.1038/nrmicro3182.

2. Yamin M A, 1981, Cellulose metabolism by the flagellate Trichonympha from a termite is independent of endosymbiotic bacteria. Science, vol.211(2): 58-59. http://dx.doi.org/10.1126/science.211.4477.58.

3. Inoue T, Moriya S, Ohkuma M, et al. 2005, Molecular cloning and characterization of a cellulase gene from a symbiotic protist of the lower termite Coptotermes formosanus. Gene, vol.349(2): 67-75.

http://dx.doi.org/10.1016/j.gene.2004.11.048.

4. Brune A, 2006, Symbiotic associations between termites and prokaryotes, in The Prokaryotes, $3^{\text {rd }}$ edn. Springer, New York, vol.1: 439-474.

http://dx.doi.org/10.1007/0-387-30741-9_17.

5. Ohkuma M and Kudo T, 1996, Phylogenetic diversity of the intestinal bacterial community in the termite Reticulitermes speratus. Applied and Environmental Microbiology, vol.62(2): 461-8.

6. Hongoh Y, Ohkuma M and Kudo T, 2003, Molecular analysis of bacterial microbiota in the gut of the termite Reticulitermes speratus (Isoptera: Rhinotermitidae), FEMS Microbiology Ecology, vol.44(2): 231-242. http://dx.doi.org/10.1016/S0168-6496(03)00026-6.

7. Yang H, Schmitt-Wagner D, Stingl U, et al. 2005, Niche heterogeneity determines bacterial community structure in the termite gut (Reticulitermes santonensis). Environmental Microbiology, vol.7(7): 916-32. http://dx.doi.org/10.1111/j.1462-2920.2005.00760.x.

8. Potrikus C J and Breznak J A, 1977, Nitrogen-fixing Enterobacter agglomerans isolated from guts of woodeating termites. Applied and Environmental Microbiology, vol.33(2): 392-399.

9. Schultz J E and Breznak J A, 1978, Heterotrophic bac- teria present in hindguts of wood-eating termites [Reticulitermes flavipes (Kollar)]. Applied and Environmental Microbiology, vol.35(5): 930-936.

10. Tholen A, Schink B and Brune A, 1997, The gut microflora of Reticulitermes flavipes, its relation to oxygen, and evidence for oxygen-dependent acetogenesis by the most abundant Enterococcus sp. FEMS Microbiology Ecology, vol.24(2): 137-149.

http://dx.doi.org/10.1111/j.1574-6941.1997.tb00430.x.

11. Leadbetter J R and Breznak J A, 1996, Physiological ecology of Methanobrevibacter cuticularis sp. nov. and Methanobrevibacter curvatus sp. nov., isolated from the hindgut of the termite Reticulitermes flavipes. Applied and Environmental Microbiology, vol.62(10): 3620-3631.

12. Leadbetter J R, Crosby L D and Breznak J A, 1998, Methanobrevibacter filiformis sp. nov., a filamentous methanogen from termite hindguts. Archives of Microbiology, vol.169(4): 287-292.

13. Leadbetter J R, Schmidt T M, Graber J R, et al. 1999, Acetogenesis from $\mathrm{H}_{2}$ plus $\mathrm{CO}_{2}$ by spirochetes from termite guts. Science, vol.283: 686-689.

14. Lilburn T G, Kim K S, Ostrom N E, et al. 2001, Nitrogen fixation by symbiotic and free-living spirochetes. Science, vol.292(5526): 2495-2498.

http://dx.doi.org/10.1126/science.1060281.

15. Wenzel M, Schoenig I, Berchtold M, et al. 2002, Aerobic and facultatively anaerobic cellulolytic bacteria from the gut of the termite Zootermopsis angusticollis. Journal of Applied Microbiology, vol.92(1): 32-40. http://dx.doi.org/10.1046/j.1365-2672.2002.01502.x.

16. Olsen R A and Bakken L R, 1987, Viability of soil bacteria: optimization of plate-counting technique and comparison between total counts and plate counts within different size groups. Microbiology Ecology, vol.13(1): 59-74. http://dx.doi.org/10.1007/BF02014963.

17. Leadbetter J R, 2003, Cultivation of recalcitrant microbes: cells are alive, well and revealing their secrets in the $21^{\text {st }}$ century laboratory. Current Opinion in Microbiology, vol.6: 274-281. http://dx.doi.org/10.1016/S1369-5274(03)00041-9.

18. Huang Z, Chen X, Shi Y, et al. 2011, Molecular analysis of some Chinese termites based on mitochondrial cytochrome oxidase (CoII) gene. Sociobiology, vol.58(1): 107-118.

19. Chen W, Wang B, Hong H, et al. 2012, Deinococcus reticulitermitis sp. nov., isolated from a termite gut. International Journal of Systematic and Evolutionary Microbiology, vol.62(1): 78-83.

http://dx.doi.org/10.1099/ijs.0.026567-0.

20. Tschech A and Pfennig N, 1984, Growth-yield increase linked to caffeate reduction in Acetobacterium woodii. Archives of Microbiology, vol.137(2): 163-167. 
http://dx.doi.org/10.1007/BF00414460.

21. Widdel F and Pfennig N, 1981, Studies on dissimilatory sulfate-reducing bacteria that decompose fatty acids. I. Isolation of a new sulfate-reducer enriched with acetate from saline environments. Description of Desulfobacter postgatei gen. nov. sp.nov. Archives of Microbiology, vol.129(5): 395-400.

22. Edwards U, Rogall T, Blöcker H, et al. 1989, Isolation and direct complete nucleotide determination of entire genes. Characterization of a gene coding for $16 \mathrm{~S}$ ribosomal RNA. Nucleic Acids Research, vol.17(19): 78437853.

23. Weisburg W G, Barns S, Pelletier D A, et al. 1991, 16S ribosomal DNA amplification for phylogenetic study. Journal of Bacteriology, vol.173(2): 697-703.

24. Ashelford K E, Chuzhanova N A, Fry J C, et al. 2005, At least 1 in 20 16S rRNA sequence records currently held in public repositories is estimated to contain substantial anomalies. Applied and Environmental Microbiology, vol.71(12): 7724-7736.

http://dx.doi.org/10.1128/AEM.71.12.7724-7736.2005.

25. Potrikus C J and Breznak J A, 1980, Uric acid-degrading bacteria in guts of termites [Reticulitermes flavipes (Kollar)]. Applied and Environmental Microbiology, vol.40(1): 117-124.

26. Hendricks C W, Doyle J D and Hugley B, 1995, A new solid medium for enumerating cellulose-utilizing bacteria in soil. Applied and Environmental Microbiology, vol.61(5): 2016-2019.

27. Cole J R, Wang Q, Fish J A, et al. 2014, Ribosomal database project: data and tools for high throughput rRNA analysis. Nucleic Acids Research, vol.41(Database issue): D633-D642.

http://dx.doi.org/10.1093/nar/gkt1244.

28. Tamura K, Peterson D, Peterson N, et al. 2011, MEGA5: Molecular evolutionary genetics analysis using maximum likelihood, evolutionary distance, and maximum parsimony methods. Molecular Biology and Evolution, vol.28: 2731-2739.

http://dx.doi.org/10.1093/molbev/msr121.

29. Thong-On A, Suzuki K, Noda S, et al. 2012, Isolation and characterization of anaerobic bacteria for symbiotic recycling of uric acid nitrogen in the gut of various termites, Microbes and Environments, vol.27(2): 186-192. http://dx.doi.org/10.1264/jsme2.ME11325.

30. Cho M J, Kim Y, Shin K, et al. 2010, Symbiotic adaptation of bacteria in the gut of Reticulitermes speratus: low endo-beta-1,4-glucanase activity. Biochemical and Biophysical Research Communications, vol.395: 432435. http://dx.doi.org/10.1016/j.bbrc.2010.04.048.

31. Chou J H, Chen W M, Arun A B, et al. 2007, Trabul- siella odontotermitis sp. nov., isolated from the gut of the termite Odontotermes formosanus Shiraki. International Journal of Systematic and Evolutionary Microbiology, vol.57(4): 696-700.

http://dx.doi.org/10.1099/ijs.0.64632-0.

32. Pace N R, Stahl D A and Lane D J, 1986, The analysis of natural microbial populations by ribosomal RNA sequences. Advances in Microbial Ecology, vol.9: 1-55. http://dx.doi.org/10.1007/978-1-4757-0611-61.

33. Fang H, Lv W, Huang Z, et al. 2015. Gryllotalpicola reticulitermitis sp. nov. isolated from a termite gut. International Journal of Systematic and Evolutionary Microbiology, vol.65(1): 85-89. http://dx.doi.org/10.1099/ijs.0.062984-0.

34. Pasti M B and Belli M L, 1985, Cellulolytic activity of actinomycetes isolated from termite (Termitidae) gut. FEMS Microbiology Letter, vol.26(1): 107-112. http://dx.doi.org/10.1111/j.1574-6968.1985.tb01574.x.

35. Roes-Hill M L, Rohland J and Burton S, 2011, Actinobacteria isolated from termite guts as a source of novel oxidative enzymes. Antonie Leeuwenhoek, vol.100(4): 589-605. http://dx.doi.org/10.1007/s10482-011-9614-x.

36. Stevenson B S, Eichorst S A, Wertz J T, et al. 2004, New strategies for cultivation and detection of previously uncultured microbes. Applied and Environmental Microbiology, vol.70(8): 4748-4755. http://dx.doi.org/10.1128/AEM.70.8.4748-4755.2004.

37. Brune A and Ohkuma M, 2011, Role of the termite gut microbiota in symbiotic digestion, in Biology of Termites: A Modern Synthesis. Springer, Dordrecht: 439-475.

38. Ohkuma M and Brune A, 2011, Diversity, structure, and evolution of the termite gut microbial community, in Biology of Termites: A Modern Synthesis. Springer, Dordrecht: 413-438.

39. Ohkuma M, Noda S and Kudo T, 1999, Phylogenetic diversity of nitrogen fixation genes in the symbiotic microbial community in the gut of diverse termites. Applied and Environmental Microbiology, vol.65(11): 4926-4934.

40. Du X, Li X, Wang Y, et al. 2012, Phylogenetic diversity of nitrogen fixation genes in the intestinal tract of Reticulitermes chinensis Snyder. Current Microbiology, vol.65(5): 547-551.

41. Eutick M L, O’Brien R W and Slaytor M, 1978, Bacteria from the gut of Australian termites. Applied and Environmental Microbiology, vol.35(5): 823-828.

42. Pasti M B, Pometto A L, Nuti M P, et al. 1990, Lignin-solubilizing ability of actinomycetes isolated from termite (Termitidae) gut. Applied and Environmental Microbiology, vol.56(7): 2213-2218. 